\title{
Abstinêncio, Fulano Malta, Ultímio e Mariano: Representações da História de Moçambique
}

\author{
Flávia Cristina Bandeca Biazetto ${ }^{1}$
}

\begin{abstract}
RESUMO: A produção literária do moçambicano Mia Couto está inserida no macrossistema de Literaturas de Língua Portuguesa e aborda questões sobre o tema da busca pela identidade. Seus textos evidenciam a diversidade cultural de seu país, tanto pelos personagens, quanto pelos espaços descritos de uma forma singular, marcada pelas brincadeiras lexicais. Este trabalho busca analisar o papel das personagens que pertencem à linhagem dos Marianos no romance Um rio chamado tempo, uma casa chamada terra, relacionando-as com momentos da História moçambicana.
\end{abstract}

ABSTRACT: The work by the Mozambican writer Mia Couto belongs to the Portuguese literary system and it approaches identity issues. In his books Mia Couto describes several places and characters in order to represent different cultures, which compose Mozambique. Moreover, he has a singular way of writing, in which he jokes with Portuguese lexicon and popular proverbs of his nation. This research aims to analyze the role of the characters that belong to Mariano's family in the novel $A$ river called time, $A$ house called land, by relating them to some periods of Mozambique History.

PALAVRAS-CHAVE: Mia Couto; personagens; História de Moçambique.

KEYWORDS: Mia Couto; characters; History of Mozambique.

O escritor moçambicano Mia Couto é reconhecido por seus romances; entretanto, sua produção literária se estende também à lírica, à crônica e à literatura infantil. Em todos os gêneros experimentados por Mia, há traços recorrentes, como a questão da identidade e a ludicidade presente em sua escrita. Os elementos estruturais de seus textos são trabalhados e articulados de tal forma que permitem evidenciar a diversidade cultural de seu país. Nesta breve exposição, será destacado o romance Um rio chamado tempo, uma casa chamada terra, mais especificamente o papel das personagens, que pertencentes à linhagem dos Marianos, dentro desta obra.

O romance aqui analisado narra o reencontro do estudante Marianinho com sua terra natal e com sua família. Depois de viver anos na cidade estudando, este personagem retorna a Luar-do-Chão, ilha em que vivem os Marianos, para o funeral de seu avô, o Dito Mariano, que não está completamente morto e sim é um "portador assintomático de vida"

\footnotetext{
${ }^{1}$ Mestranda em Estudos Comparados de literaturas de Língua Portuguesa, FFLCH-USP. Pesquisa: Análise comparativa entre as crônicas de Mia Couto e Antônio Lobo Antunes. E-mail: fla_bandeca@yahoo.com.br
} 
(COUTO, 2003: p.37). Enquanto espera a morte efetiva do avô para a realização dos rituais tradicionais de morte, o protagonista vai re-descobrindo as tradições da ilha e desvelando os segredos de seus familiares.

No que se refere aos personagens, pode-se começar pela análise de Abstinêncio. Este, o primogênito dos Marianos, era um tipo "magro por timidez: para ser menos visto" (COUTO, 2003: p.119) e apresentado como uma pessoa que "se dobrava, fazendo vênia no torto e no direito". (COUTO, 2003: p.16). Por meio desta descrição, nota-se um tom de submissão que envolve o personagem, possibilitando interpretá-lo como uma representação do povo moçambicano durante os anos do colonialismo.

Para melhor entender este aspecto é necessário assinalar alguns pontos que marcaram o governo colonial. Segundo Fanon, havia no regime colonial uma inferiorização da cultura do colonizado que era reduzida a "usos e costumes". Desta forma, o colonizador podia justificar sua atuação como agente civilizador, aumentando assim seu poder na colônia. Já o colonizado, sofria uma "epidermização" do complexo de inferioridade, ou seja, passavam a se sentir como tal, destituindo a sua humanidade.

Abstinêncio era um assimilado e desempenhava uma função pública. Cabe aqui explicar que no Regime Colonial, para atingir tais cargos era comum que os colonizados adotassem certos hábitos dos colonizadores, tendo em vista a obtenção do estatuto de assimilado que era um documento que permitia certos direitos, dentre os quais ter pequenos cargos públicos. Assim, ao se submeter a uma mudança de hábito forçada pelos portugueses, Abstinêncio abre mão, em certa medida, de sua própria cultura, assim se abstendo de uma parte de si mesmo.

Isso é percebido, por meio de suas ações ao longo do romance, por exemplo, em um dado momento do romance, o narrador nos relata que Abstinêncio havia se negado a sair de um encosto da repartição, onde trabalhava, enquanto pintores pintavam-na de branco. Sua resistência resulta na marca de seu corpo naquele pedaço da parede; como se ele próprio fosse a marca viva do regime colonial.

$\mathrm{O}$ ato de pintar as paredes de branco em uma tentativa de camuflar o passado é impedido - a maneira de Abstinêncio - , pois esquecer esse tempo era como se abandonasse uma parte da própria personagem, que levava consigo as frustrações desse período. A medida que a narrativa avança, o narrador desvela todas as frustrações de Abstinêncio, que eram tanto de ordem amorosa, como política, visto que ele invejava seu irmão Fulano que fora um guerrilheiro nas lutas de Libertação. 
Fulano Malta, segundo filho de Mariano, era um ex-guerrilheiro que havia lutado na guerra contra o colonialismo. Por acreditar na essência da luta e dos homens, ele fora à guerra, contrariando o seu pai, Dito Mariano.

O ponto de partida para a análise desta personagem é o seu próprio o nome: Fulano Malta. O primeiro nome, Fulano, é um substantivo usado na língua portuguesa para fazer uma nomeação vaga a alguém. Já o segundo nome, Malta, é usado para designar pessoas que levam uma vida nômade ou para nomear um grupo de pessoas.

Sob este ângulo, pode-se interpretar a palavra Fulano como referência aos guerrilheiros que lutaram a fim de derrubar o regime colonial, e depois da guerra tornaramse heróis anônimos. Já o nome Malta pode aludir aos grupos de guerreiros. Ou, ainda, estar relacionado com o desejo do personagem de viver fora da ilha, no continente, assim tendo seus anseios vagando de forma nômade entre Luar-do-Chão e a cidade. É fato que o personagem não foi muitas vezes para o continente, "mas no escondido da noite ele sonhava visitar aquelas luzes do lado de lá”. (COUTO, 2003: p.66)

Fulano é uma personagem que se por um lado lutou pelos ideais de libertação que acreditava, por outro ansiava por conhecer mais os costumes do povo que vivia no continente, mas simultaneamente repelia esta idéia. Isso é mostrado por meio do episódio, em que ele some com os livros do filho, que eram "como armas apontadas" para a família. É possível interpretar essas "armas" como o símbolo da cultura ocidental que os livros representam: a escrita. Ele mostra uma curiosidade por esse mundo da escrita, mas ao mesmo tempo afasta de si mesmo esta vontade, como se esta proximidade com a cultura do continente fosse arrancar-lhe a identidade com a ilha, onde as tradições africanas eram mantidas.

O personagem tem consciência da real situação política, entendendo que o modelo de governo, seguido pelos novos líderes moçambicanos após a libertação, era similar à forma exercida pelos portugueses no período colonialista. Daí, suas desavenças com seu irmão Ultímio. Mesmo diante da situação de corrupção e exploração instituída depois do fim do Regime Colonial, Fulano acredita na possibilidade da instauração de outros parâmetros sociais, como nos sugere a seguinte passagem: convertendo em pássaro. Já toda ave, ela reganha o céu e se extingue. (COUTO, 2003: p.246) 
Esse trecho permite interpretar uma crença no fim de qualquer tipo de aprisionamento. No entanto, o mesmo personagem sente uma tristeza em não ter sido pai, ou seja, ter descendentes que dêem continuidade aos seus sonhos de liberdade e a toda a ideologia de sua geração.

O mais novo dos três, Ultímio, é um representante do novo governo - como já foi dito anteriormente. Guiado pela cobiça, ele vê Luar-do-Chão como um negócio lucrativo, e nem se importa com as pessoas e com a tradição que há nela, ou melhor, ele nem se percebe como parte integrante da ilha e dos seus habitantes. Além disso, ele menospreza os rituais tradicionais praticados por seus familiares.

O motivo real que o leva à ilha é sua intenção de vender Nyumba-Kaya, a casa de sua família, para construir um hotel. A semi-morte de seu pai e, por conseqüência, o estado emocional de sua mãe não o sensibiliza e nem tira o foco de suas ambições.

Outro aspecto importante, que envolve este personagem na narrativa, é sua relação com a questão da raça. A postura de Ultímio sobre a questão racial é no mínimo intrigante, podemos exemplificá-la com a passagem em que ele descobre que, em um acidente, fora salvo por uma doação de sangue de um branco, ele reage de uma forma ambígua. Ele “nega, ajuntados os pés, cruzados os dedos. Primeiro ri-se. (COUTO, 2003: p.215).

Esse riso e sua atitude de cruzar os dedos mostram uma certa satisfação com a revelação. Assim, somando a reação desta cena com outros indícios do texto, é possível interpretar que seu desejo de estar no lugar do colonizador era tão grande, que logo que o Regime Colonial terminou, ele passou a agir como aqueles que invejava; adotando uma postura tão violenta quanto a dos portugueses.

A violência de Ultímio não está somente na ganância que o move, mas também no alheamento em relação ao outro. Ele não vê as outras personagens como pessoas, mas simplesmente como um suporte que pode auxiliá-lo a atingir seus interesses. Para ele não importa o que o coletivo possa sofrer, somente lhe interessa os seus desejos individuais. Ao ser indiferente aos habitantes da ilha, ele os anula em suas humanidades, adotando uma postura semelhante a de um colonizador.

A próxima geração é aqui representada por Mariano, um jovem universitário, que foi educado na cidade. Ao retornar à ilha para acompanhar o funeral de seu avô, Dito Mariano, ele vai desvendando fatos que o ajudam a descobrir sua própria história e origem. Suas descobertas fazem-no refletir sobre a história de seu povo e sobre as tradições locais, que ele já havia abandonado em virtude de sua vivência na cidade moderna. 
Por um lado, seu próprio nome carrega as marcas do passado colonial: "A ilha era nossa origem, o lugar primeiro do nosso clã, os Malilanes. Ou, no aportuguesamento: os Marianos" (COUTO, 2003: p18). Desta forma, o seu nome é a prova da imposição cultural de Portugal. Já por outro, atrelá-lo ao seu passado, pois é o mesmo nome de seu avô, dando assim uma idéia de continuidade, inseparável da questão da ancestralidade.

Neste romance, há um fato intrigante: Mariano toma consciência de toda a história da ilha por meio de cartas misteriosas, supostamente, escritas por seu avô. Todavia, esse se encontra "clinicamente morto", sendo impossível escrever as epistolas. Além disso, provavelmente, o avô não dominava a escrita. Ao receber as cartas, Mariano percebe que é sua letra ali grafada.

No entanto, Mariano passou muitos anos fora da ilha e não teria o conhecimento da história tão detalhada, como é descrita nas cartas. Esse fato leva ao questionamento: quem realmente escreve as cartas?

Assim, os leitores são remetidos à idéia de uma memória coletiva, que se estende do ancestral, o avô, para o neto.

Nessa complexa proposição da existência, que coloca a morte dentro da vida, os ancestrais negro-africanos constituem, juntamente com a sociedade e sem dela separar-se, um princípio histórico material e concreto capaz de contribuir para a objetivação da identidade profunda de um dado complexo étnico e das suas formas de ações sociais. (LEITE, 1995).

Por meio desse elemento fantástico do romance que se refere à autoria das cartas, infere-se um dado da sociedade tradicional africana, o qual mostra que a mesma é constituída de vivos e mortos que atuam ativamente em seu cotidiano. Mariano parece tomar consciência disso e todos os significados dos rituais tradicionais presentes na ilha, por meio de seu diálogo epistolar com seu avô.

A história de Moçambique é retomada à medida que Marianinho vai desvendando os mistérios e frustrações da história pessoal de seus familiares. Este trabalho de resgate possibilita a grande revelação sobre o seu nascimento e sua real origem. Após descobrir que na verdade era filho de Dito Mariano, finalizando assim todos os mistérios que envolvem o enredo, o personagem aqui referido volta ao continente. Entretanto, em seu regresso se mostra uma outra pessoa, enriquecida pela sabedoria tradicional e pelo resgate da história de sua família. 
Este personagem carrega em si elementos da cultura tradicional da ilha e, simultaneamente, aspectos da cultura do continente modernizado. É possível fazer a leitura de que ele simboliza uma geração que tem consciência destes dois ângulos da sociedade moçambicana e não as hostiliza de forma hierárquica.

Os personagens aqui analisados representam a própria História de Moçambique; passando pelos diferentes períodos: o colonial (Abstinêncio), o de lutas (Fulano Malta), o frustrante pós-colonial (Ultímio), e por fim, o atual (Mariano), no qual tradição e modernidade convivem e mostram a pluralidade e complexidade de ser moçambicano.

\section{Referências bibliográficas}

CANDIDO, Antônio. A personagem do romance. In A personagem de ficção. São Paulo: Perspectiva, 1976.

CHAVES, Rita. Mia Couto voz nascida da terra. In Novos estudos: $n^{\circ} 49$, novembro de 1997, p.243- 256.

. Frantz Fanon colonialismo, violência e identidade cultural. In Margens da cultura. São Paulo: Boitempo, 2004.

COSTA, Jurandir Freire. Razões Públicas, emoções privadas. Rio de Janeiro: Rocco, 1999.

COUTO, Mia. Um rio chamado tempo, uma casa chamada terra. São Paulo: Companhia das letras, 2003.

FANON, Frantz. Os condenados da terra. Rio de Janeiro: Civilização Brasileira, 1979.

LEITE, F. África. In: Revista do Centro de estudos africanos, São Paulo: $18-19$ (1) 103-11, $1995 \backslash 1996$. 